\title{
EXPERIMENTAL CARDITIS. CHANGES IN THE MYOCARDIUM AND PERICAR- DIUM OF RABBITS SENSITIZED TO STREPTOCOCCI
}

\author{
By BENJAMIN M. BAKER, CAROLINE BEDELL THOMAS, ANd RAWLEY M. PENICK, JR. \\ (From the Cardiographic Laboratory of the Johns Hopkins Hospital and University, Baltimore)
}

(Received for publication March 8, 1935)

Many kinds of organisms have been introduced through different channels into various experimental animals in an attempt to reproduce the lesions characteristic of rheumatic fever. The results of these researches are summarized thoroughly in the comprehensive reviews of Thomson and Thomson (9) and of Gross, Loewe and Eliasoph (1). Although certain abnormalities of the heart have been produced, chiefly by streptococci, these lesions have not resembled those of human rheumatic fever enough to attract wide attention. Recently Rinehart, Connor and Mettier $(5,6)$ have used haemolytic streptococci of beta type to infect guinea pigs which were maintained on a diet deficient in vitamin $C$. They have observed valvular lesions quite regularly in these animals and, in some, myocardial lesions which are strikingly similar to those of human rheumatic carditis.

During recent years many authors, chief of which are Swift and his associates (8) have emphasized the possible rôle of allergy in the production of some of the features of rheumatic fever. Seegal, Seegal and Jost (7) have produced extraordinary lesions of the myocardium, pericardium and the aorta in rabbits made hypersensitive to egg white. After having produced in animals a hypersensitive state by the repeated subcutaneous injection of egg white they injected a solution of egg white directly into the pericardial sac. In 88 per cent of the animals extensive inflammatory changes in the myocardium or pericardium resulted which were not found in the hearts of animals not previously sensitized.

It occurred to us that it would be of interest to repeat these observations using bacteria instead of egg white. This report deals with experiments in which a beta haemolytic streptococcus was employed.

\section{METHOD}

The strain of streptococcus $\left(\mathrm{SD}_{2}\right)$ used in our experiments was cultivated from the inflamed tonsils of a patient ill with acute haemorrhagic nephritis. As described by Hansen-Pruss, Longcope and O'Brien (2) this organism $\left(\mathrm{SD}_{2}\right)$ produces a filtrate which is neutralized consistently in skin tests by convalescent scarlatinal serum and does not produce skin reactions in doses of 0.5 cc. in normal rabbits. Healthy young rabbits weighing from 2000 to 2500 grams were used. The rabbits were obtained in litters, and litter mates were divided as evenly as possible between the sensitized and control groups.

The rabbits were given repeated intracutaneous injections of $0.1 \mathrm{cc}$. of a saline suspension of living beta haemolytic streptococci $\left(\mathrm{SD}_{2}\right)$. The suspension was obtained by centrifuging for twenty minutes at high speed a twenty-four hour culture of the organism grown in beef infusion broth of $\mathrm{pH} 7.6$ at $37^{\circ} \mathrm{C}$. The supernatant fluid was decanted and replaced by an equivalent amount of sterile normal salt solution.

Twenty-two of twenty-eight rabbits thus prepared received from four to six injections; two received three injections and four received seven injections. (Table I.) Half of the rabbits re-

TABLE I

Number of injections

\begin{tabular}{|c|c|c|c|c|c|}
\hline Number of injections.... & 3 & 4 & 5 & 6 & 7 \\
\hline Number of rabbits & $2 *$ & $7^{*}$ & 9 & 6 & 4 \\
\hline
\end{tabular}

* In each of these groups one rabbit had received ten injections of 0.01 cc. of streptococcus $\mathrm{SD}_{2}$ intracutaneously over a period of a month which had failed to produce any sensitivity as measured by skin reactions; after an interval of nine weeks the present series of 3 and 4 injections of 0.1 cc. was given.

ceived the complete series of injections during a period of from nine to twelve days; the other half were sensitized over a period of from seven to twenty-two days. (Table II.) The size of the skin reactions, twenty-four hours after the 
TABLE II

Period of sensitization

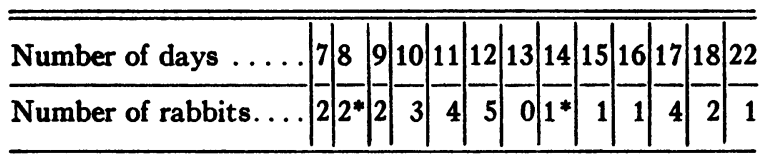

* See footnote to Table I.

injections were made, was the measure used in estimating whether or not skin sensitivity had been produced. Two diameters of the resulting wheals were recorded in centimeters but no attempt was made to measure accurately the oedema or assign degrees of intensity to the erythema produced. (Table III.)

TABLE III

Twenty-four hour readings

Average size of first reactions in all animals. . . $2.0 \times 1.6 \mathrm{~cm}$. Average size of last reactions in all animals. . . $3.5 \times 2.8 \mathrm{~cm}$. Average size of smallest reactions in all animals. $1.4 \times 1.2 \mathrm{~cm}$. Average size of largest reactions in all animals $.4 .1 \times 3.1 \mathrm{~cm}$.

Since the number of organisms introduced into the skin at each injection was relatively large, the contrast between the size of the first and last wheals produced was not as great as it might have been had smaller doses been employed. Sensitivity, as reflected by the size of the skin reaction, did not always mount in a straight line. The initial response was often greater than some reactions produced by subsequent injections. After the first response the wheal would often increase beyond the original level only to diminish in size or in some instances to increase again if further injections were made. In general, there were three criteria by which an animal was considered to be sensitized. (1) If it had received three or preferably more injections which had produced wheals greater in diameter than one centimeter. (2) If it had shown a maximal reaction following some one of the injections after the first. (3) If the last injection was followed by a reaction larger than one centimeter in diameter and definitely larger than the original one.

When an animal had received repeated skin injections and was considered sensitive by the criteria just given, a heat killed culture of the streptococcus $\left(\mathrm{SD}_{2}\right)$ employed was injected directly into the pericardial sac. A twenty-four hour culture of $\mathrm{SD}_{2}$ in beef infusion broth of $\mathrm{pH} 7.6$ was killed by heating it in a water bath at $56^{\circ} \mathrm{C}$. for one hour; sterility was then demonstrated by cultures. The organisms were not resuspended in salt solution before pericardial injection.

After the final sensitizing injection a period of from one to seven days elapsed before pericardiotomy was performed. (Table IV.) Under

TABLE IV

Days elapsing between last injection and operation

\begin{tabular}{l|l|l|l|l|l|l|l|l}
\hline \hline Number of days............ & 1 & 2 & 3 & 4 & 5 & 6 & 7 \\
\hline Number of rabbits.......... & 6 & 3 & 6 & 8 & 0 & 2 & 3 \\
\hline
\end{tabular}

ether anaesthesia the thorax was opened and the parietal pericardium was picked up in small forceps. In this way the operator could be reasonably certain that the inoculum was introduced accurately into the pericardial sac. Two cc. of the killed culture were introduced into each animal in the series, both into the controls as well as the sensitized animals. Three animals, previously sensitized, died within an hour after operation and were discarded. None of the control animals died. The majority of the sensitized animals were sacrificed on the third day after operation. A few were sacrificed sooner and a few were kept for as long as six days. All of the controls were sacrificed on the third day. A characteristic protocol follows.

PROTOCOL I

White rabbit number 41

A. Sensitization: Uniform doses of $0.1 \mathrm{cc}$. saline suspension of twenty-four hour cultures of living beta haemolytic streptococcus $\left(\mathrm{SD}_{2}\right)$ were injected intracutaneously.

$$
\begin{aligned}
& \text { Dose Date given } \\
& 1 \text {..... March 26, } 1932 \\
& 2 \ldots \ldots \text { March 28, } 1932 \\
& 3 \text {...... March 30, } 1932 \\
& 4 \ldots \ldots \text { April 2, } 1932 \\
& 5 \ldots \ldots \text { April 7, } 1932 \\
& 6 \ldots \ldots \text { April } 10,1932
\end{aligned}
$$

Twenty-four hour reaction

$1.5 \mathrm{~cm} . \times 2.4 \mathrm{~cm}$.

$1.4 \mathrm{~cm} . \times 1.5 \mathrm{~cm}$.

$2.0 \mathrm{~cm} . \times 2.5 \mathrm{~cm}$.

$2.0 \mathrm{~cm} . \times 2.5 \mathrm{~cm}$.

$3.5 \mathrm{~cm} . \times 5.5 \mathrm{~cm}$.

$2.5 \mathrm{~cm} . \times 3.0 \mathrm{~cm}$.

B. Operation: April 13, 1932 . Under ether anaesthesia open pericardiotomy was performed and $2.0 \mathrm{cc}$. of vaccine prepared from beta haemolytic streptococcus $\left(\mathrm{SD}_{2}\right)$ was injected into the pericardial sac.

C. Autopsy: April 16,1932. The animal was sacrificed and the thorax opened. The parietal pericardium was opaque and covered with a thick fibrinous exudate. The pericardial sac was greatly distended with an excess of opaque fluid which gave no growth on culture. Direct 


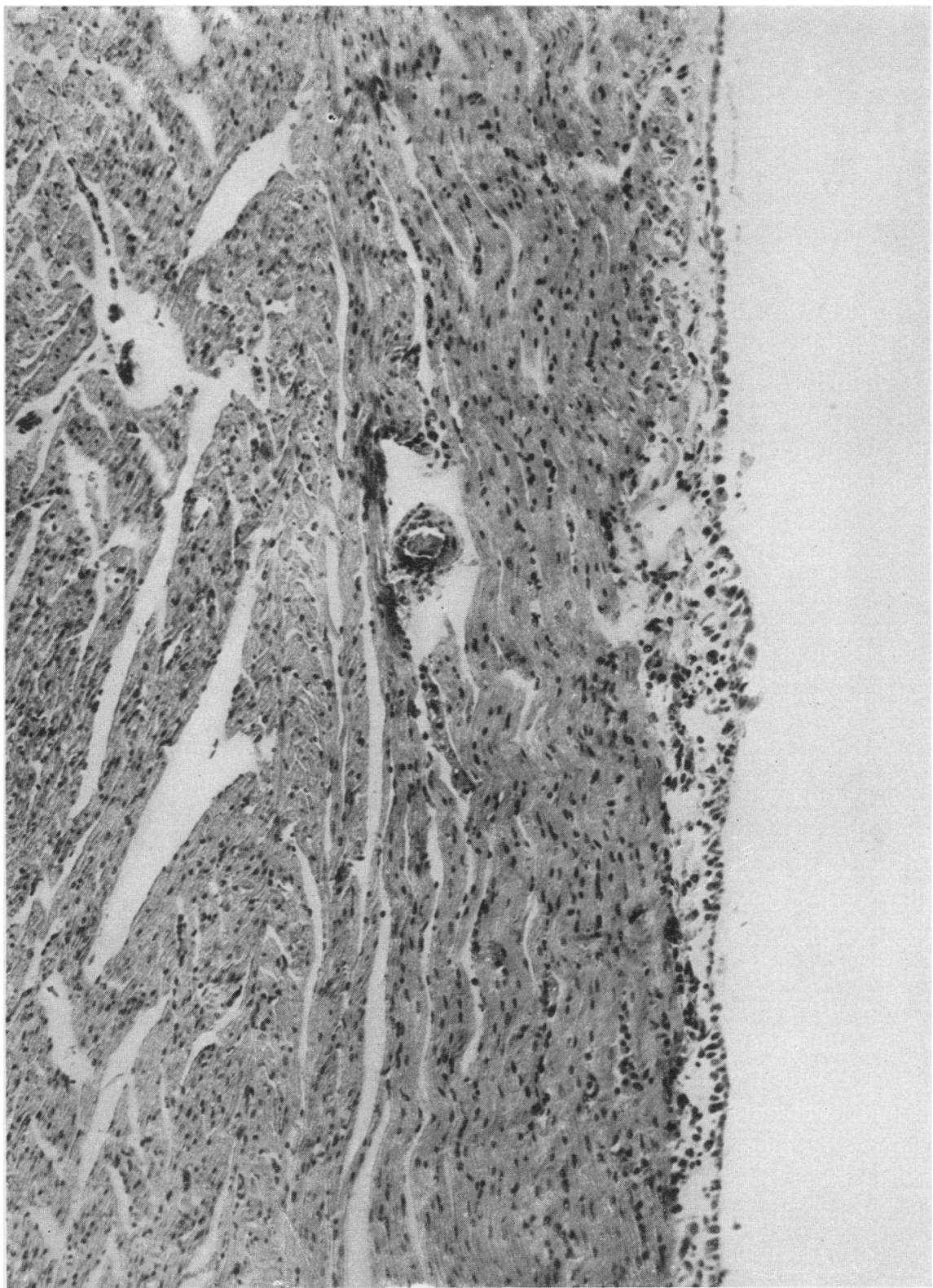

Fig. 1. $\times 100$. Control Animal.

No skin injections. 2 cc. $\mathrm{SD}_{2}$ vaccine intrapericardially, slight reaction in epicardium, myocardium normal.

smears of this fluid showed masses of cells about half of which were polymorphonuclear leukocytes and about half small lymphocytes. No organisms were seen in the fluid with appropriate stains. The parietal pericardium was greatly thickened and covered with a dense grayish exudate. The heart seemed to be dilated. The valves appeared normal. No thrombi were seen in the larger coronary vessels. Microscopical sections revealed an intense diffuse inflammatory reaction involving the pericardium and both the ventricular and auricular myocardium.

\section{RESULTS}

At autopsy cultures were made from the pericardial sacs of both series of animals. In only one instance was there a secondary infection and the organism recovered was a staphylococcus. This animal was discarded. The remaining cultures were sterile. In all of the control animals the hearts appeared grossly normal. In the sensitized animals the gross appearances at autopsy 
varied considerably. In thirteen there was no abnormality. In seven there were slight deviations from the normal appearance and in eight there were extensive changes. In four of these there were quite large pericardial effusions. The pericardial surfaces were greatly thickened and were covered with heavy fibrino-purulent exudate. Direct smears from the fluid in those instances in which there were pericardial effusions showed about an equal number of mononuclear cells and polymorphonuclear leukocytes. No bacteria were seen in stained preparations of pericardial fluid. In the hearts which were grossly abnormal the larger coronary vessels were studied as carefully as their small size would permit. No thrombi were found. No gross abnormalities were detected on any of the heart valves.

Sections for microscopical study were made from the hearts of eighty-nine animals. Thirtyone normal, healthy young rabbits served as one control group. The tiny scars, areas of vacuolization of muscle fibers and minute collections of round cells appearing in the sections of hearts in this series were considered normal and served as a standard with which to compare other sections. Ten animals were sensitized by repeated skin injections, as previously described, and were then sacrificed, without further procedure. Microscopically all of these hearts were normal. A third, and the most important control group, consisted of twenty normal rabbits that received no skin injections whatever. By open pericardiotomy as described above they received $2 \mathrm{cc}$. of a killed culture of $\mathrm{SD}_{2}$ directly into the pericardial sac and were sacrified approximately seventy-two hours later. Sections from the hearts of fifteen of these animals were recorded as normal. In the remaining five there were lesions recorded as "slight" which will be discussed below.

The microscopical appearance of the hearts of the twenty-eight animals, sensitized before the intrapericardial injection of vaccine, are remarkably different from those of the controls. Eighteen of these show extensive abnormalities which far exceed those noted in any of the controls. Four show changes roughly comparable to "slight" changes noted in the control group (mentioned in the paragraph above). The remaining six are considered normal. In the eighteen hearts considered extensively diseased the le- sions varied considerably both in character and in distribution. In some the entire heart was involved while in others the lesions were focal in distribution. In some hearts the pericardial surfaces were extensively diseased whereas the myocardium was relatively spared and vice versa. There follows a tabulation of the changes noted in the eighteen hearts considered extensively diseased.

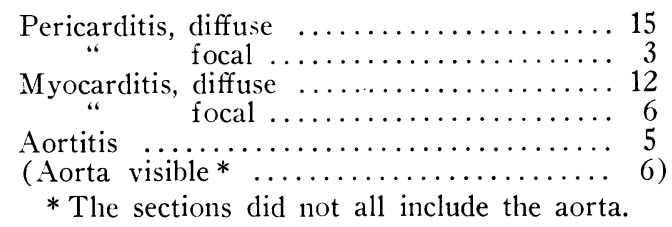

In most instances the pericardial membranes were greatly thickened and covered with dense fibrinous exudate. In the earliest lesions polymorphonuclear leukocytes occurred in considerable numbers but in most instances the cells were

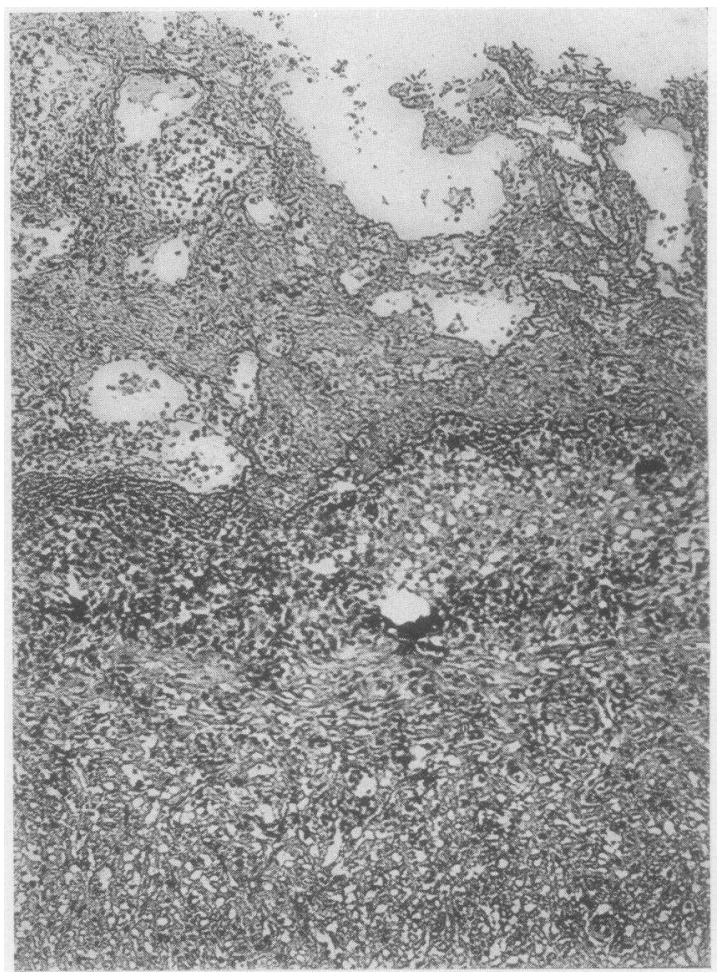

Fig. 2. $\times 100$. Sensitized Animal.

2 cc. SD. vaccine intrapericardially. Intense pericardial reaction with dense fibrin deposit infiltrated by relatively few small round cells. Haemorrhage. Connective tissue cells in great abundance. Invasion of inflammatory reaction into adjacent myocardium. 
chiefly small round cells with little cytoplasm and uniform dark nuclei. It is worthy of note that the number of leukocytes was far less than one would expect in such an intense inflammatory reaction with tremendous outpouring of fibrin. Perhaps the most striking feature of the reaction was the tendency to the formation of scar tissue and the whole inflammatory reaction was densely invaded by young fibroblastic cells. In Figure 2 the epicardial reaction is shown, and as can be seen clearly the inflammatory changes extend deep into the adjacent myocardium destroying muscle fibers and bringing about cloudy swelling and loss of striation in the more normal fibers near the periphery of the myocardial lesions. Here also there is great invasion of young fibroblasts and rapid formation of scar tissue with destruction of the normal intracellular substance.

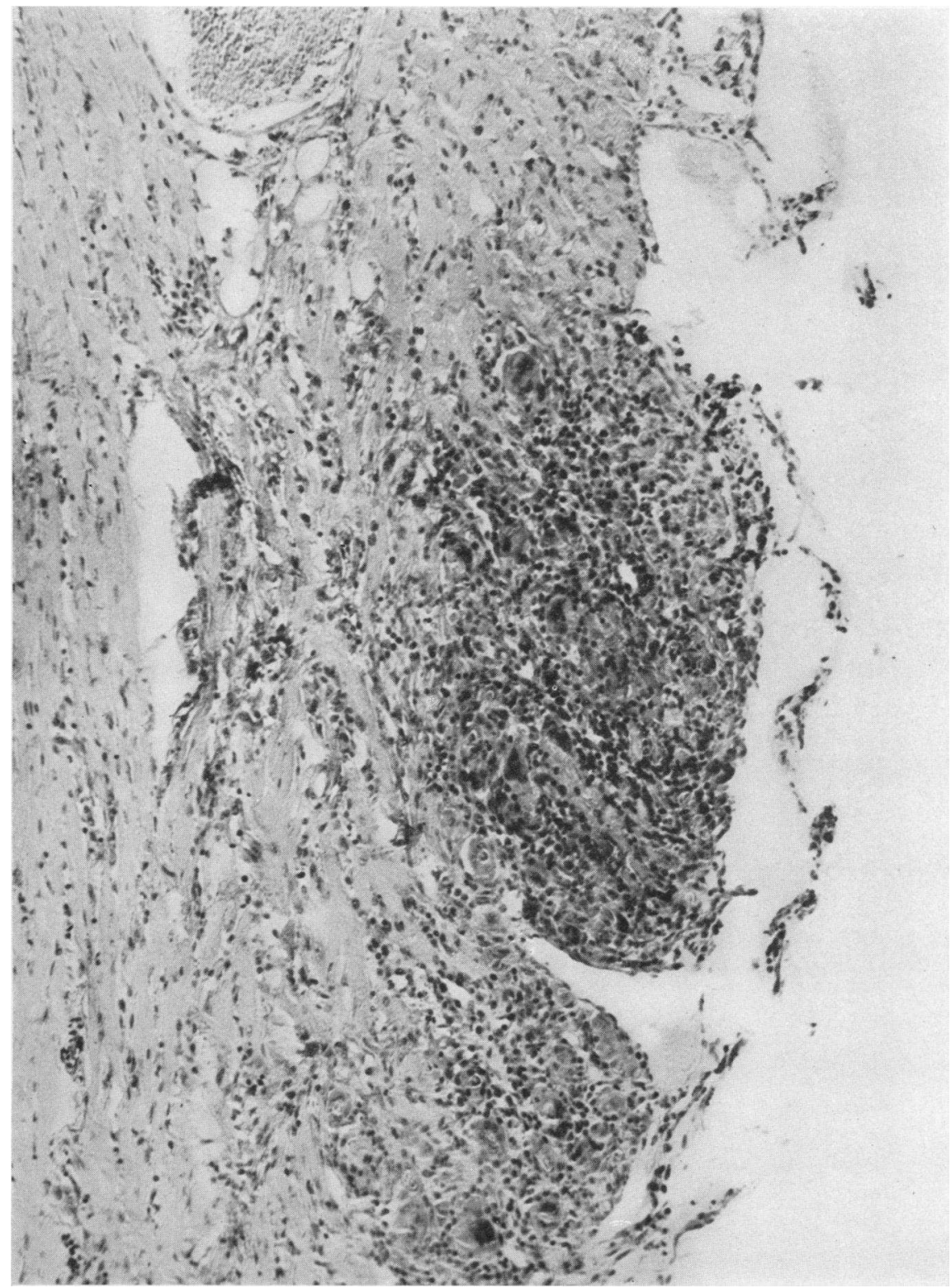

Fig. 3. $\times 100$. Sensitized Animal.

2 cc. $\mathrm{SD}_{2}$ vaccine intrapericardially. Focal epicardial reaction. Small round cells, giant cells, connective tissue cells, muscle necrosis. 
While the majority of hearts from the sensitized group showed widespread pericardial changes, in some the pericardial reaction was focal in distribution and in others it was uniformly very slight. Figure 3 illustrates a focal epicardial lesion. There is necrosis of the underlying muscle fibers with many small round cells and numerous young connective tissue cells. As can be seen clearly in the illustration there are many giant cells. In some of the hearts with relatively little pericardial reaction the myocardium was extensively altered. Frequently this myocardial change extended down to the subendocardium and in many there was extensive destruction of the papillary muscles. Figure 4 shows a subendocardial lesion, which is almost precisely like the epicardial lesion illustrated in Figure 3.

A different type of reaction is illustrated in

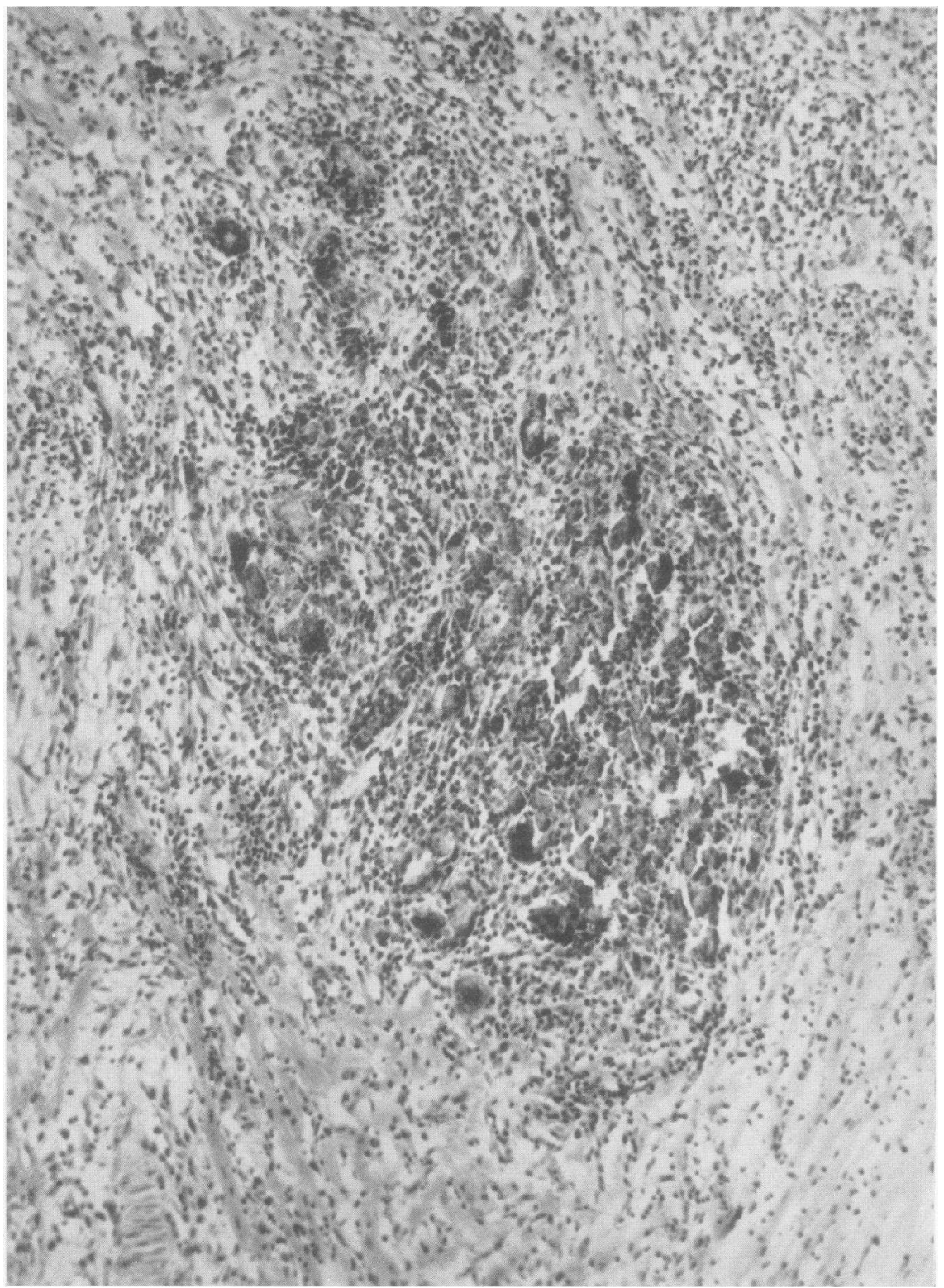

Fig. t. $\times 100$. Sexsitized Aximal.

2 cc. SD. vaccine intrapericardially. Focal reaction similar to Figure 3 located subendocardially. 
Figure 5 in which a whole section of muscle from the depth of the left ventricle is almost completely destroyed. There is widespread necrosis of muscle with oedema, some haemorrhage, invasion of small round cells and fibroblasts.

Careful search of the blood vessels did not reveal any thrombi. In some of the sections the same type of inflammatory reaction was seen in the loose tissue about the aorta and in some the adventitia was likewise involved. None of the valves showed any significant change though often the diffuse changes noted above involved the myocardium at valvular junctions. Careful examination of the vessels revealed some perivascular lesions but in comparison to other widespread changes they are rare.

\section{DISCUSSION}

When rabbits were made skin sensitive by repeated skin injections with living beta haemolytic streptococci and a vaccine prepared from the homologous organism was injected into the peri-

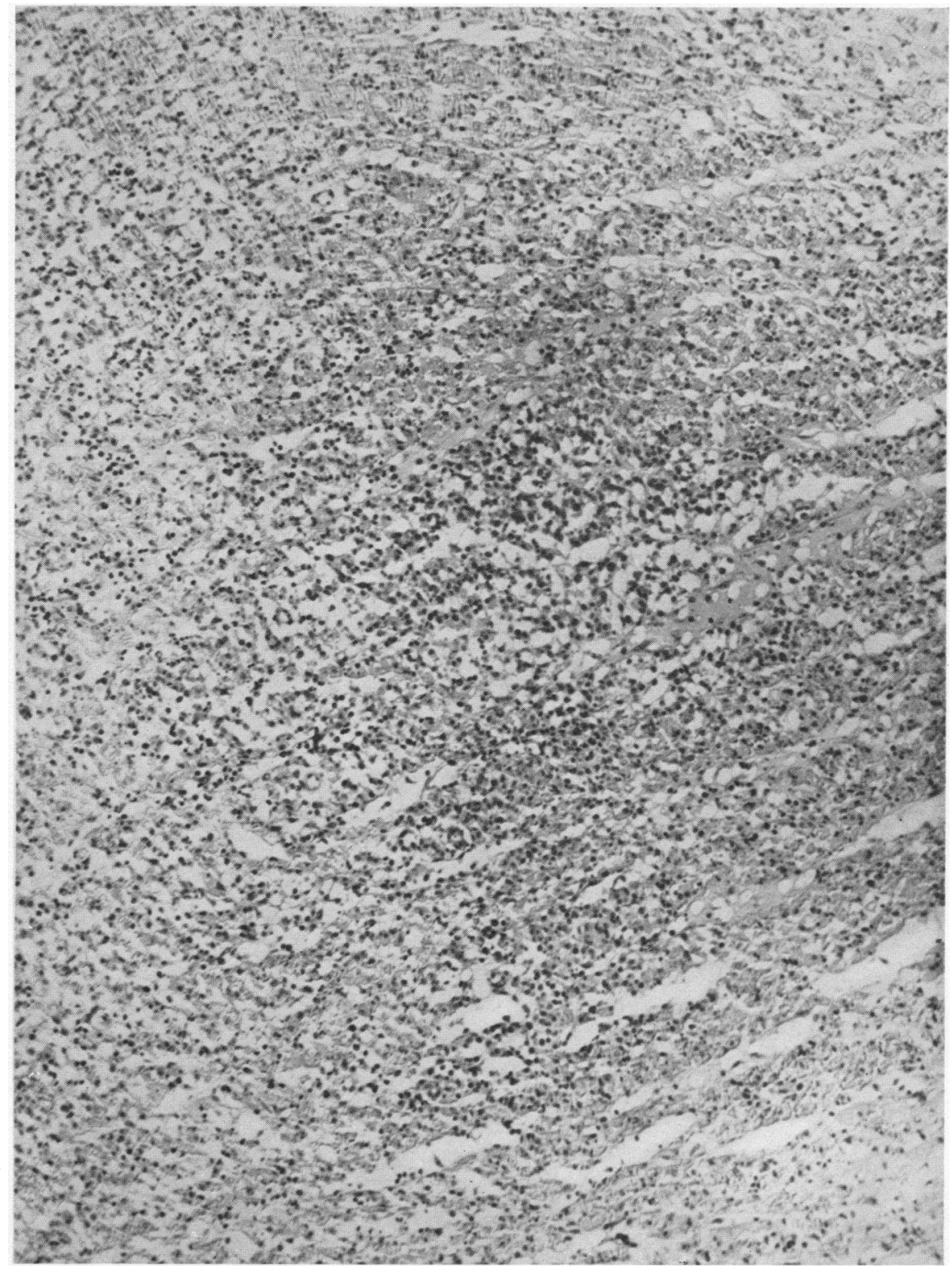

Fig. 5. $\times 100$. Sensitized Animal.

2 cc. $\mathrm{SD}_{2}$ vaccine intrapericardially. Widespread diffuse inflammatory reaction of myocardium, necrosis of muscle, oedema, haemorrhage, round and connective tissue cell invasion. 
cardial sacs an intense inflammatory reaction occurred in the myocardium or pericardium or both in 64 per cent of the twenty-eight animals. The hearts of normal animals receiving no skin injections but otherwise similarly treated were not comparably diseased. In some of the abnormal hearts the lesions were chiefly confined to the pericardium, in others to the myocardium, and in still others there was a widespread carditis involving not only the pericardium and myocardium but also the intrapericardial aorta. The lesions had no specific characteristic but were in the nature of an intense inflammatory reaction with oedema, haemorrhage, and outpouring of leukocytes and small round cells and a notable tendency to very early repair. In a few of the older lesions there was calcification. The pericardial reactions were noteworthy in that they consisted of a great outpouring of fibrin, rapid repair but a relatively unimpressive leukocytic response. In some animals, sacrificed on the second day after intrapericardial injection, the lesions contained a moderate number of polymorphonuclear leukocytes, but in the vast majority the cells were predominantly small round cells and young connective tissue cells. Eosinophils were prominent in the lesions in only one section, and there was no apparent explanation for this finding.

As has been previously emphasized care was used in testing the sterility of the intrapericardial inoculum, and careful cultures from the pericardium at autopsy were, except as noted, uniformly sterile. Bacterial stains have been made of the tissues from the sensitized series of animals, and occasional organisms were found in various types of lesions. Inasmuch as the great majority of lesions were free from demonstrable organisms, and the bulk of the injected killed organisms had disappeared in the few days elapsing between the intrapericardial injection and the autopsy, it is assumed that the organisms seen were the last representatives of the injected material which had not yet been destroyed. As noted by Seegal, Seegal and Jost (7) it is at once apparent that in the pericardium the antigen comes directly into contact with the tissues. The explanation which they offered for the reactions deep in the myocardium was that the antigen was taken up by the lymphatics. This seems to us to be the most satisfactory explanation for the re- sults obtained in our experiments. Noteworthy changes did not occur in any of the animals not previously sensitized. While 64 per cent of the sensitized animals reacted to the intrapericardial injections of vaccine with a pronounced inflammatory response in the heart, others whose skin sensitivity was equally great, gave no reaction whatever. The extent of cardiac involvement did not, therefore, parallel the degree of skin reaction. Neither the severity of the original skin response nor the number of injections could be correlated with the magnitude of the resulting cardiac lesions.

In addition to the work of Seegal, Seegal and Jost (7), other observers have noted changes in the heart when an homologous antigen is injected into a previously sensitized animal. Longcope (4) observed small round cell accumulations in the heart when horse serum was given intravenously to sensitized animals. Klinge (3) sensitized animals to egg white and then injected egg white into the joints. Changes in the valves and myocardium resulted which it was stated bore considerable resemblance to the cardiac lesions of rheumatic fever. Vaubel (10) confirmed this work.

There is nothing specific about the lesions described in this study. The type of pericarditis is very similar to the pericarditis seen in acute rheumatic fever, but it lacks 'any lesions specific for this disease. The changes in the myocardium consist in a widespread inflammatory reaction which bears no resemblance to the specific lesions of rheumatic fever.

\section{SUM MARY}

(1) When a heat killed culture of beta haemolytic streptococcus is injected intrapericardially into rabbits sensitized to the same organism, an extensive carditis results.

(2) The intrapericardial injection of this organism into unsensitized animals produces no such changes.

(3) The changes in the hearts of the sensitized animals are characterized by an extensive, nonspecific, inflammatory reaction.

We wish to express our appreciation to Dr. Edward P. Carter for his interest and advice. 


\section{BIBLIOGRAPHY}

1. Gross, L., Loewe, L., and Eliasoph, B., Attempts to reproduce rheumatic fever in animals. J. Exper. Med., 1929, 50, 41.

2. Hansen-Pruss, O. C., Longcope, W. T., and O'Brien, D. P., Skin reactions to filtrates of haemolytic streptococci in acute and subacute nephritis. J. Clin. Invest., 1929, 7, 543.

3. Klinge, F., Die Eiweissüberempfindlichkeit (Gewebsanaphylaxie) der Gelenke. Experimentelle pathologisch-anatomische Studie zur Pathogenese des Gelenkrheumatismus. Beitr. z. path. Anat. u. z. allg. Path., 1929, 83, 185.

4. Longcope, W. T., The effect of repeated injections of foreign protein on the heart muscle. Arch. Int. Med., 1915, 15, 1079.

5. Rinehart, J. F., Connor, C. L., and Mettier, S. R., Further observations on pathologic similarities between experimental scurvy combined with infection, and rheumatic fever. J. Exper. Med., 1934, 59, 97.

6. Rinehart, J. F., and Mettier, S. R., The heart valves and muscle in experimental scurvy with superim- posed infection, with notes on the similarity of the lesions to those of rheumatic fever. Am. J. Path., 1934, 10, 61.

7. Seegal, D., Seegal, B. C., and Jost, E. L., The Arthus phenomenon. Local anaphylactic inflammation in the rabbit pericardium, heart and aorta. J. Exper. Med., 1932, 55, 155.

8. Swift, H. F., Derick, C. L., and Hitchcock, C. H., Rheumatic fever as a manifestation of hypersensitiveness (allergy or hyperergy) to streptococci. Tr. A. Am. Physicians, 1928, 43, 192.

9. Thomson, D., and Thomson, R., An historical survey of researches on the rôle of the streptococci in acute articular rheumatism or rheumatic fever. Ann. Pickett-Thompson Research Lab. (Monograph), 1928, 4, 1.

10. Vaubel, E., Die Eiweissüberempfindlichkeit (Gewebshyperergie) des Bindegewebes. II. Experimentelle Untersuchungen zur Erzeugung des rheumatischen Gewebsschadens im Herzen und in den Gelenken. Beitr. z. path. Anat. u. z. allg. Path., 1932, 89, 374. 